\title{
Overview of the Conversion of Traditional Power Grid to Internet Energy
}

\author{
Vugar Abdullayev, Ranjeet Pratap Singh Bhadouria \\ ${ }^{I}$ Lecturer Ph.D. Associate Professor, Azerbaijan State Oil and Industry University, Azerbaijan, Baku, abdulvugar@mail.ru \\ ${ }^{2}$ Assistant professor, Department of Electronics \& Comm. Engineering, IPS CTM, Gwalior, r.pratap7872@gmail.com \\ *Correspondence: Vugar Abdullayev; Email- abdulvugar@mail.ru
}

\begin{abstract}
In the information society, no human activity stands still, including the electric power industry. As a result, there has been a shift from a traditional grid architecture to a new information and communication technology architecture. The object of the study of this article is a smart power supply system. The purpose of the study is to consider problems for implementing the concepts of "Smart Grid" and "Internet of energy." To do this, a brief overview was made of the traditional electricity supply system, as well as promising renewable energy sources and its promising directions. In order for several RSE to exist in the same power grid without any problems, it is necessary to use energy routers that are able to connect several power grids operating on different sources. The received system monitor by the power grid management systems (SCADA, distributed control system). There are also discussed the SCADA tasks and features. The above all leads to the implementation of two innovative concepts in the field of energy: Smart Grid and Internet energy.
\end{abstract}

Keywords: Electricity, Fourth industrial revolution, Smart Grid, Energy Router, SCADA, Internet of Energy.

\section{Introduction}

Global events of informatization and computerization of society and all areas of human activity characterized the second half of the 20th century. Now there are processes of digitalization and intellectualization of society and all areas of human activity. This can all consider prerequisites of the fourth industrial revolution (Industry 4.0).

\section{ARTICLE INFORMATION}

Author(s): Vugar Abdullayev, Ranjeet Pratap Singh Bhadouria;

Received: November 19, 2020; Revision: December 15, 2020; Published:

December 25, 2020;

e-ISSN: 2347-470X; Paper Id:IJEER-080401;

Citation: https://doi.org/10.37391/IJEER.080401

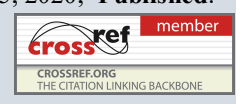

Webpage-link: http://ijeer.forexjournal.co.in/archive/volume-8/ijeer-080401.html

Industry 4.0 is a coming revolution where there is assumed mass application of Cyber-Physical Systems (CPS) in production and to serve human needs. [1]

CPS is a system consisting of two components: physical and digital. The physical component is the physical world in which physical processes take place. A digital (information) component is an information system responsible for processing data on relevant physical processes. Smart sensors and activators implementing the IoT concept serve as a connecting component between these components [2]

In other words, the principle of cyber-physical systems looks like this: the "brain" of the system advances information technology, which receives data from sensors that monitor current physical processes. [1]

There are several basic technical prerequisites that have made CPS possible:
- The first is an increase in the number of devices with embedded processors and storage: touch networks operating in all long technical infrastructures; medical equipment; smart homes, etc.

- The second is integration, which allows you to achieve the greatest effect by combining individual components into large systems: the Internet of Things (IoT), World Wide Sensor Net, Smart Building Environment, defense systems of the future.

- The third is the limitation of human cognitive abilities, which evolve more slowly than machines. In this regard, there is certainly a moment when people are no longer able to cope with the amount of information required for decision-making, and some of the actions need to transfer to the CPS, taking the person out of the control loop (human out of loop).

- At the same time, in some cases, CPS can strengthen the analytical abilities of a person, so there is a need to create interactive systems of a new level that keep a person in the control loop (human in the loop). [3]

\section{Traditional and alternative power generation}

Many countries use traditional power grid to provide electricity to the population. The traditional electricity industry uses non-renewable (coal, oil, gas, uranium) and renewable (hydropower, wood) sources. The main problems of traditional electricity can consider the following: exhaustion of traditional energy sources and negative impact on the environment. [4,5]

These problems create appropriate vulnerabilities in electricity systems. There are being introduced renewable 
(alternative) sources of electricity (RSE) to eliminate them. Unlike traditional sources, they are inexhaustible and have less negative effects on the environment. Alternative sources of electricity include the following [6]:

- Solar energy is RSE produced directly from solar radiation. The conversion of solar energy into electric energy is due to solar panels; [7]

- Wind energy is a RSE that applies the kinetic energy of atmospheric masses to convert them into electrical energy; [8]

- Tidal energy is a kind of RSE derived from tidal energy; [9]

- Energy derived from waves is an inexhaustible source of energy derived from the waves of the seas and oceans. The application of wave energy is now at the stage of experimental research; [10]

- Geothermal energy is RSE, which is based on the use of thermal energy from the Earth's bowels to generate electricity. [11]

The main drawback of RSE is their dependence on weather conditions and seasonality. In other words, during certain climatic conditions, some sources are preferable to others. For this reason, it makes sense to create hybrid power plants that combine several renewable and traditional sources of energy. [12]

The priorities for renewable energy in 2020 are as follows: modernization of energy storage systems, Blockchain technology, ensuring cybersecurity of the power system,

Modernization of energy storage systems. The main problem of RSE is dependence on weather conditions. One solution to this problem is hybrid power plants, which combine several energy sources. Developments are under way on competitive power storage facilities capable of providing high reliability;

Blockchain technology. Blockchain will allow end-users to buy and sell energy in the optimal time using the Internet of Things and related devices. In essence, it will be a network in which all participants are equal and which makes it possible to trade energy-to-energy companies and even individual customers among themselves. The advantages of blockchain are also that operations occur in real time and are "transparent." This builds confidence between the participants in the sale.

Ensuring cybersecurity of the power system. On the eve of the fourth industrial revolution, the importance of computing resources increases, and then there is the need to ensure the cybersecurity of this system.

\section{Energy router}

Since the electric power generated by power plants of different energy sources have incompatible parameters, there is necessary the unit capable of combining such power plants into a single network for the operation of the electric power grid. Such the unit is an energy router.

An energy router is a cyber-physical device whose goal is to control and distribute electricity in electric power grid. [13] The energy router architecture includes three components:
1. The power component is the component responsible for the operation of the power current in the power grid;

2. A measuring component is a component that collects data on the parameters of a power component;

3. The digital component includes computing resources necessary to ensure reliable and efficient operation of the power router. [14]

The functions of the power router are to detect, isolate and repair damaged sections of the network, as well as to control the power and quality of electricity in the network. The power router, as a communication device, allows you to configure various mains topologies.

The immediate effect of the power getter will be:

- for owners of small generation sources - in simplification of circuit solutions due to connection of sources, accumulators and load to one unit without additional devices; increase of efficiency of electric energy usage due to complete control automation;

- for "smart networks" - in simplifying the connection of electrical equipment with various output parameters and ensuring high quality of electric energy;

- for responsible facilities - in reducing risks of damage and loss of information from power supply failure.

The functions of the power router are to detect, isolate and repair damaged sections of the network, as well as to control the power and quality of electricity in the network. The power router, as a communication device, allows you to configure various mains topologies.

\section{Management of power grid}

On the eve of the fourth industrial revolution, the electric power industry, like other industries, needs automation. Given that many power grids are now becoming "smart," the question arises of their control. Two main categories of control systems use to implement the control of electric power systems: distributed control systems (DCS) and SCADA. [15]

DCS is CPs that control a continuous industrial process. DCS is mainly used in chemistry and petrochemicals, oil processing and oil production, gas processing and gas production, metallurgy, food industry, energy supply, etc., where the industrial process is constant. [15]

Distributed control systems have the following characteristics:

- Local independence. Nodes in a distributed system must be independent or autonomous. Local independence means that that node monitors all operations on a node.

- No support on the central assembly. Local independence assumes that all nodes in a distributed system should treat as equal. Therefore, there should be no access to the "central" or "main" node in order to obtain some centralized service.

- Continuous operation. Distributed systems should provide a higher degree of reliability and availability.

- Independence from location. Users should not know exactly where the data is stored physically.

- Independence from fragmentation. The system supports fragmentation independence if this variable - the relationship can divide into parts or fragments when organizing its physical storage. In this case, the data can be 
stored in the place where it is most often used, which allows you to achieve localization of most operations and reduce network traffic.

- Independence from replication. The system supports data replication if a given stored relationship variable - or generally a given fragment of a given stored relationship variable - can be represented by multiple individual copies or replicas that are stored on multiple separate nodes.

- Distributed query processing. The bottom line is that a query may require access to multiple sites. In such a system, there may be many possible methods of forwarding data to enable the request to execute.

- Operating system independence. Possibility of DBMS operation under different operating systems. [16]

SCADA (Supervisory Control and Data Acquisition) is a tool for creating and controlling systems for collecting, processing, displaying and archiving information about an observed object in real time. [1]

The main task of SCADA systems is to collect information about many remote objects coming from control points, and display this information in a single control center. In addition, the SCADA system should provide long-term archiving of the received data. The dispatcher often has the ability not only passively observe the object, but also to manage it, responding to various situations.

Among the features of SCADA are the following:

- SCADA systems must have a person (operator, dispatcher);

- Any improper impact can lead to a failure of the control object or even catastrophic consequences;

- The manager is generally responsible for managing a system that, under normal conditions, only occasionally requires tuning parameters to achieve optimal performance;

- Most of the time, the manager passively watches the displayed information. The manager's active participation in the management process is infrequent, usually in the event of critical events - failures, emergency and emergency situations, etc;

- Operator actions in critical situations can be severely limited in time (a few minutes or even seconds).

\section{Smart Grid}

Introduction of control systems of power grid allows implementing the concept "Smart Grid". The Smart Grid - the power supply system of the next generation including the advanced information and communication technologies for collection of data on power production and energy consumption. According to the European Commission dealing with issues of development of the technological platform in the field of power, Smart Grid has the following characteristics:

- Flexibility.: The power supply network has to be capable to adapt under needs of power consumers;

- Availability: The power supply network has to provide reliable connection of new consumers, including the user RSE;
- Reliability: The power supply network has to guarantee reliability and safety supply of the electric power to consumers of electricity;

- Profitability: At realization of the smart power grid the innovative technologies allowing reducing financial and material inputs for effective management and regulation by network are used.

The advantages of an intelligent network include [17].

1. Improving reliability;

2. Increased physical, operational and cyber security and resilience to attacks or natural disasters.

3. self-repair or ease of repair, especially remote repair;

4. Increasing the amount of information available to consumers on their energy consumption.

5. Improving energy efficiency along with the environmental benefits derived from such efficiency;

6. Integration of a greater proportion of renewable energy sources, which by their nature may be unpredictable;

7. Integration of plug-in electric vehicles; and,

8. Reduce peak demand.

\section{Internet of Energy}

Listed above allow to implement the concept "The Internet of Energy". The Internet is a global information network where there is an exchange of information between its participants. Analogy has the Internet of Energy similar, the electric power only exchanges and there will be she within the country or the concrete region. The main prerequisites for realization of the Internet of energy are the following factors:

- Transformation of parameters of demand of electroconsumers: growth of variety and requirement of transition to digital demand;

- Falling of efficiency: low loading of capacities and increase of expenses of performance of power supply networks;

- Power transformation: active applications of alternative energy sources, introductions of information and communication technologies, the distributed power;

- Development of the removed and isolated territories.

The main feature of the Internet of Energy is decentralization of the power supply network, hundred promotes creation of the distributed system of supply with the electric power. This feature reduces values of large power plants that work on hydrocarbons or are nuclear power plants or hydroelectric power stations, and along with it increases the values of averages or small power plants that are based on RSE.

There are formed some kind of "separate" power supply networks (Micro-grid) which cover the small territory at design of the distributed system of supply with the electric power. There is possible to use above the mentioned Energy Router for exchange of the electric power between them and associations, them in the general power supply network.

Since renewable energy is used to generate electricity, and they depend on weather conditions, there is a need to introduce an electricity storage system. Energy Internet storage makes the network efficient, ensuring energy quality, reliable supply and stable network operation. Energy storage is useful when the grid is in tense mode and cannot balance 
supply and demand alone in peak demand. In this case, the battery together with the grid can supply power simultaneously, thereby smoothing the power supply to prevent possible blackout. It can also solve the problem of voltage surge, sagging and transient power outages. The storage can be installed by the utility company as a backup power source on the distributed side or can also be stored by the consumer as a backup battery in an electric vehicle. The customer can charge the battery in their electric vehicle in the shutdown hour, and they can sell power to the grid in peak demand that maximizes economic benefit.

Since the nature of renewable is discontinuous. Solar panels do not generate electricity at night, and wind power cannot supply energy when there is no wind. Thus, when the solar or wind power is in the operating state providing the excess power, the power can be stored in a large memory and used when the distributed power generating devices do not supply the power. Therefore, this improves the reliability of the grid by improving the stability of the grid. Commonly used storage devices are battery, supercapacitor, fuel cell, flywheel, compressed air and pumped hydro.

\section{Conclusion}

1. The approach of the fourth industrial revolution allows the electric power industry to realize the idea of "Internet of Energy." To do this, the article examined the main components of this idea: energy router, SCADA, RSE, Micro-grid and Smart Grid.

2. Special attention also paid to traditional and smart power grids. In particular, there consider the problems of traditional power grids, features and types of RSE, features of Smart Grid.

3. The main component of the Internet of energy is the energy router. In this article, there consider the components of the energy router, as well as its functions.

\section{References}

[1] Abdullayev V., Khalilov M. (2019). Advantages of implementing cyber-physical systems in electric power industry. Energetikanın problemləri №4 129-133.

[2] Dragicevic N., Ullrich A., Tsui E., Gronau N. (2019). $A$ conceptual model of knowledge dynamics in the Industry 4.0 smart grid scenario. Knowledge Management Research \& Practice 18(2) 199-213.

[3] Rossit D., Tohme F., Frutos M. (2018). Industry 4.0: Smart Scheduling. International Journal of Production Research 57(12) 3802-3813.

[4] Kruse J., Schafer B., Witthaut D. (2020). Predictability of Power Grid Frequency. IEEE Access PP 4(99) 1-12.

[5] Mar A., Pereira P., Martins J. (2019). A Survey on Power Grid Faults and Their Origins: A Contribution to Improving Power Grid Resilience. Energies 12(24) 1-21.
[6] Azad K., Saha M. (2012). Wind Power: A Renewable Alternative Source of Green Energy. International Journal of Basic and Applied Science 1(2) 193-199.

[7] Adelakun N., Olanipekun B. (2019). A Review of Solar Energy. SSRN Electronic Journal 6(12) 11344-11347.

[8] Haan B. (2020). An Exploration of Wind Energy. Undergraduate Journal of Mathematical One + Two 10(2) 1-11.

[9] Ali L., Mohmmed H., Anssari O. (2019). Modeling and Simulation of Tidal Energy. Journal of Engineering and Applied Sceinces 14(11) 3698-3706.

[10] Sellamuthu P. (2018). Modeling and Pricing of Energy Derivative Market. International Journal of Engineering \& Technology 7(10) 148-156.

[11] Mikhaylov A. (2020). Geothermal Energy Development in Iceland. International Journal of Energy Economics and Policy 10(4) 31-35.

[12] Sau M., Patoding E., Kasa A. (2020). Solar-Diesel Hybrid Power Plant Battery Charging Systems. IOP Conference Series Materials Science and Engineering 885 1-7.

[13] Shuo Li, Zichen Li, Pengfei Li, Yanchi Zhang, Da Xie (2020). Energy Flow Analysis of the Multi-Energy Energy Router. IOP Conference Series Earth and Environmental Science 467 1-6.

[14] Yingshu Liu, Chunping Bi, Yao Zhao, Yao Wu, Xi Chen (2018). Energy Router with Load Switching Functionality. Energy Procedia 158 2561-2566.

[15] Cardwell L., Shebanow A. (2013). The Efficacy and Challenges of SCADA and Smart Grid Integration https://www.researchgate.net/publication/274720206_The_Efficacy_ and_Challenges_of_SCADA_and_Smart_Grid_Integration

[16] Yagyaeva L., Perukhin M., Abdulfattah O. (2013). Distributed control system. Bulletin of Kazan Technological University 9 291293.

[17] Wazeer A., Singh A. (2018). Smart grid. International Journal of Advance Research in Science and Engineering 7(5) 201-205. 